\title{
ATIVIDADE DE CAMPO E JOGO DIDÁTICO NO ENSINO DE ECOLOGIA PARA TURMAS DO ENSINO MÉDIO
}

\author{
Luan Cerqueira de Oliveira ${ }^{1}$ \\ Laís Amorim Ferreira ${ }^{2}$ \\ Mariana Aparecida Lordeiro ${ }^{3}$ \\ Elaine Gimenez Guimarães ${ }^{4}$ \\ Erika Aparecida Silva de Freitas 5 \\ Elias Terra Werner ${ }^{6}$
}

Resumo: Ao estudar a Ecologia deve se utilizar a aula teórica, onde se apresenta os conceitos e aula prática, onde há a apresentação dos fenômenos por meio de experimentação, aulas de campo etc. Este trabalho tem o objetivo de realizar uma atividade de campo para apresentar os fenômenos da ecologia e utilizar um jogo didático na avaliação do tema. Para isso os alunos de duas turmas da primeira série do ensino médio foram levados ao jardim da escola, para que os mesmos pudessem distinguir as relações ecológicas presentes em um ambiente em que tinham contato. Após o estudo, as turmas foram divididas em quatro grupos para jogarem o Jogo da Memória Ecológico, no qual deviam formar os pares das relações ecológicas. A atividade de campo mostrou-se adequada para que os alunos distinguirem as relações ecológicas no ambiente natural e a partir do jogo da memória foi possível observar as dificuldades dos alunos ao diferenciar as relações.

Palavras-chave: Relações ecológicas; Biosfera; Aula prática; Espaço não-formal; Biologia.

\footnotetext{
${ }^{1}$ Graduando em Ciências Biológicas Licenciatura/Departamento de Biologia/Centro de Ciências Exatas, Naturais e da Saúde/Universidade Federal do Espirito Santo - UFES, Brasil. E-mail: luaano@hotmail.com.

2 Graduanda em Ciências Biológicas Licenciatura/Departamento de Biologia/Centro de Ciências Exatas, Naturais e da Saúde/Universidade Federal do Espirito Santo - UFES, Brasil. E-mail: lais-guvi@hotmail.com.

${ }^{3}$ Graduanda em Ciências Biológicas Licenciatura/Departamento de Biologia/Centro de Ciências Exatas, Naturais e da Saúde/Universidade Federal do Espirito Santo - UFES, Brasil. E-mail: mariana.lordeiro@gmail.com.

${ }^{4}$ Graduanda em Ciências Biológicas Licenciatura/Departamento de Biologia/Centro de Ciências Exatas, Naturais e da Saúde/Universidade Federal do Espirito Santo - UFES, Brasil. E-mail: elainegimenezg@hotmail.com.

5 Docente/Escola Estadual de Ensino Fundamental e Médio Aristeu Aguiar, Brasil. E-mail: erikasfbr@yahoo.com.br.

6 Professor Doutor/Departamento de Biologia/Centro de Ciências Exatas, Naturais e da Saúde/Universidade Federal do Espirito Santo - UFES, Brasil. E-mail: eliaswerner12@gmail.com.
} 